\title{
Protein extracted from Porphyra yezoensis prevents cisplatin-induced nephrotoxicity by downregulating the MAPK and NF- $\kappa B$ pathways
}

\author{
IN-HYE KIM $^{1 *}$, MI-JIN KWON $^{2 *}$, JAE-HUN JUNG $^{2}$ and TAEK-JEONG NAM ${ }^{1,2}$ \\ ${ }^{1}$ Cell Biology Laboratory, Institute of Fisheries Sciences, Pukyong National University, Busan 46041; \\ ${ }^{2}$ Department of Food Science and Nutrition, Pukyong National University, Busan 48513, Republic of Korea
}

Received June 13, 2017; Accepted October 20, 2017

DOI: $10.3892 /$ ijmm.2017.3214

\begin{abstract}
Acute renal failure is a serious complication of treatment with the anticancer drug cisplatin. Cisplatin exerts a cytotoxic effect on renal cells by inducing apoptosis through activating the tumor suppressor p53, nuclear factor- $\kappa \mathrm{B}(\mathrm{NF}-\kappa \mathrm{B})$ and mitogen-activated protein kinase (MAPK)/p38 pathways. Effects of protein extracts of the brown seaweed Porphyra yezoensis (P. yezoensis) on cytotoxicity, inflammation and cell proliferation have been reported; however, the effects of P. yezoensis protein (PYP) extract on cisplatin-induced renal injury have remained elusive. The present study investigated the effects of PYP on cisplatin-induced nephrotoxicity in the HK2 human proximal tubular epithelial cell line. PYP treatment reduced cisplatin-induced apoptosis and death of HK2 cells by restoring the B-cell lymphoma-2 (Bcl-2)-associated $\mathrm{X}$ protein $(\mathrm{Bax}) / \mathrm{Bcl}-2$ imbalance, cytochrome $c$ release and caspase- 3 activation. In addition, PYP activated the redox-sensitive transcription factor $\mathrm{NF}-\kappa \mathrm{B}$ via stimulating the nuclear translocation of p65 in HK2 cells. PYP also restored renal antioxidant levels and increased the total and nuclear accumulation of NF erythroid 2-related factor 2 in HK2 cells. PYP markedly attenuated cisplatin-induced p38, MAPK and c-Jun N-terminal kinase phosphorylation. Furthermore, treatment with PYP ameliorated cisplatin-induced renal cell damage by upregulating antioxidant defense mechanisms and downregulating the MAPK and $\mathrm{NF}-\kappa \mathrm{B}$ signaling pathways. In addition, mice were divided into three treatment groups (control, cisplatin and PYP + cisplatin) and the effects of PYP were evaluated in a mouse model of cisplatin-induced acute
\end{abstract}

Correspondence to: Professor Taek-Jeong Nam, Department of Food Science and Nutrition, Pukyong National University, 45 Yongso-ro, Nam-gu, Busan 48513, Republic of Korea

E-mail: namtj@pknu.ac.kr

*Contributed equally

Key words: Porphyra yezoensis protein, acute renal failure, cisplatin, nephrotoxicity, mitogen-activated protein kinase, nuclear factor- $\kappa \mathrm{B}$ kidney injury. The concentrations of blood urea nitrogen and serum creatinine in the PYP + cisplatin group were lower than those in the cisplatin group. The mRNA expression levels of inflammatory factors interleukin-6 (IL-6), IL-1 $\beta$, tumor necrosis factor- $\alpha$ and monocyte chemoattractant protein- 1 in the kidney tissues of the PYP + cisplatin group were also lower than those in the cisplatin group. These results suggest that PYP treatment had a preventive effect on nephrotoxicity, specifically by downregulating the MAPK and $\mathrm{NF}-\kappa \mathrm{B}$ signaling pathways and the mRNA levels of inflammatory genes.

\section{Introduction}

Aging is defined as a time-dependent degenerative process caused by accumulated damage that leads to cellular dysfunction, tissue damage and ultimately death $(1,2)$. Aging of the kidney is associated with structural changes and functional decline (3), which render the elderly more vulnerable to stress factors, including heart failure, dehydration and hypertension, eventually leading to the development of chronic kidney disease $(4,5)$. The kidney has an essential role in the aging process, and renal function has been suggested to be an important predictor of longevity $(4,6)$. Furthermore, with aging, several structural and functional changes reportedly occur in renal glomeruli and in proximal tubular epithelial cells (7).

Acute kidney injury (AKI) occurs when there is a rapid decline in kidney function (8). In general, AKI affects proximal tubular epithelial cells. In addition, activated immune cells produce a number of inflammatory mediators and reactive oxygen species (ROS) that may cause tubular cell damage $(8,9)$. AKI may be triggered by multiple stimuli, including ischemia, nephrotoxins, radiocontrast media and bacterial endotoxins $(8,10,11)$. Nuclear factor erythroid 2-related factor $2(\mathrm{Nrf} 2)$ and nuclear factor $-\kappa \mathrm{B}(\mathrm{NF}-\kappa \mathrm{B})$ are representative transcription factors that function in transcriptional adaption to chemical stress $(10,12)$.

Cisplatin is one of the most widely used and effective drugs for the treatment of various types of solid tumor $(13,14)$. Cisplatin-induced renal injury may be pathophysiologically classified into the following four types: Tubular toxicity, vascular damage, glomerular injury and interstitial injury $(14,15)$. The stepwise and complex processes that result in renal damage 
involve accumulation of potentially toxic compounds in the tubular fluid, which then diffuse into the highly permeable tubular cells (13). Numerous studies have demonstrated that several mechanisms, including oxidative stress, DNA damage and inflammatory responses, mediate cisplatin-induced nephrotoxicity $(13,16)$. The key pathological occurrences in cisplatin-induced nephrotoxicity are renal tubular cell injury and death $(14,17)$.

Brown algae may represent a natural renewable source of novel therapeutic agents, as they are rich in functional bioactive substances, including sulfated polysaccharides, carotenoids, dietary fiber and proteins (18-28). However, despite the increased rate of discovery of biologically active substances from marine resources, little is known regarding the potential effects of seaweeds in terms of changes in renal structure and function during cisplatin treatment (29-31).

Previous studies by our group reported on the cellular and molecular effects of peptide and hydrophilic protein extracts of the brown seaweed Porphyra yezoensis (P. yezoensis) based on analyses of cytotoxicity $(20,32)$, inflammation (33-37) and cell proliferation (38-41). However, the biological effects of $P$. yezoensis protein (PYP) on cisplatin-induced renal injury have remained elusive. In the present study, PYP, a specific active factor, was obtained from $P$. yezoensis through water-based extraction followed by sequential ammonium sulfate precipitation. The therapeutic potential of PYP in reducing cisplatin-induced AKI during chemotherapy was assessed using the HK2 human proximal tubular epithelial cell line as well as model mice.

\section{Materials and methods}

Preparation of PYP. PYP was prepared according to a previous protocol (37), with slight modifications. P. yezoensis was desalted by washing and then lyophilized. A crude aqueous extract was prepared by mixing the $P$. yezoensis powder with distilled water (DW) and incubating the resulting mixture at room temperature for $4 \mathrm{~h}$. The aqueous extract was clarified by centrifugation and filtered to remove any insoluble material. The crude extract was subjected to $80 \%$ ammonium sulfate saturation and then centrifuged at $5,000 \mathrm{x} \mathrm{g}$ for $30 \mathrm{~min}$ at $4^{\circ} \mathrm{C}$. The precipitate was suspended in the minimum volume of DW and dialyzed for $48 \mathrm{~h}$ at $4^{\circ} \mathrm{C}$ against $2,000 \mathrm{ml}$ of DW. The dialyzed sample was lyophilized for 3 days and the residue was stored at $-70^{\circ} \mathrm{C}$ until further use. The purity and molecular weight of PYP were assessed by sodium dodecyl sulfate-polyacrylamide gel electrophoresis (SDS-PAGE).

Cell culture and treatment with PYP. The HK2 immortalized human proximal tubular epithelial cell line (no. CRL-2190) was obtained from the American Type Culture Collection (Manassas, VA, USA). Cells were cultured in Dulbecco's modified Eagle's medium (Invitrogen; Thermo Fisher Scientific, Inc., Waltham, MA, USA) supplemented with $10 \%$ fetal bovine serum (GenDepot, Inc., Barker, TX, USA) and antibiotics $(50 \mu \mathrm{g} / \mathrm{ml}$ penicillin, $25 \mu \mathrm{g} / \mathrm{ml}$ amphotericin B and $50 \mu \mathrm{g} / \mathrm{ml}$ streptomycin). Prior to incubation with cisplatin (Sigma-Aldrich; Merck KGaA, Darmstadt, Germany), cells were pretreated with various concentrations of PYP for the indicated durations.
Cell viability assay. Cell viability was assessed using a CytoX cell viability assay kit (CYT3000; LPS solution, Daejeon, Korea). Cells were seeded in 96-well plates at $4 \times 10^{4}$ cells/well and allowed to attach for $24 \mathrm{~h}$. Attached cells were treated with cisplatin (0-40 $\mu \mathrm{M})$ or PYP $(0-100 \mu \mathrm{g} / \mathrm{ml})$ in serum-free medium (SFM) for $24 \mathrm{~h}$. The CytoX solution was added to the cells, followed by incubation for $1 \mathrm{~h}$, and the absorbance of each well was then measured at $450 \mathrm{~nm}$ using a microplate reader (Gen 5; Epoch BioTek Instrument, Inc., Winooski, VT, USA). In addition, cell morphological changes were observed under a light microscope (magnification, x200) using a Nikon inverted Eclipse TS100-F microscope system (Epi-Fluorescence attachment; Nikon Corp., Tokyo, Japan).

Protein extraction and western blot analysis. HK2 cells were grown to $80 \%$ confluence in $100 \mathrm{~mm}$ dish plates. Attached cells were treated with PYP $(0-100 \mu \mathrm{g} / \mathrm{ml})$ in SFM for $24 \mathrm{~h}$ and cisplatin $(20 \mu \mathrm{M})$ for $8 \mathrm{~h}$. After treatment, the cells were washed twice with phosphate-buffered saline (PBS), harvested and lysed in radioimmunoprecipitation assay buffer (50 mM Tris, pH 7.4, 1 mM EDTA, 150 mM sodium chloride, $1 \%$ nonidet-40 and $0.25 \%$ sodium deoxycholate) containing a protease inhibitor cocktail (Geno Technology Inc., St. Louis, MO, USA). The lysate was centrifuged at $9,750 \mathrm{x}$ g for $10 \mathrm{~min}$ at $4^{\circ} \mathrm{C}$ and the supernatants were used for western blot analysis.

In addition, cytoplasmic and nuclear lysates were separated using an NE-PER ${ }^{\circledR}$ extraction reagents kit (78833; Pierce; Thermo Fisher Scientific, Inc.) according to the manufacturer's protocol. To isolate mitochondria, cells were lysed using a Dounce homogenizer in buffer containing $20 \mathrm{mM}$ 4-(2-hydroxyethyl)-1-piperazineethanesulfonic acid, $\mathrm{pH} 7.5$, $250 \mathrm{mM}$ sucrose, $20 \mathrm{mM}$ potassium chloride, $1.5 \mathrm{mM}$ magnesium chloride, $1 \mathrm{mM}$ phenylmethylsulfonyl fluoride, $10 \mu \mathrm{g} / \mathrm{ml}$ aprotinin and $10 \mu \mathrm{g} / \mathrm{ml}$ leupeptin at $4^{\circ} \mathrm{C}$. The cell lysates were centrifuged at $6,000 \mathrm{x} \mathrm{g}$ for $10 \mathrm{~min}$ to remove unbroken cells and nuclei. The supernatants were then centrifuged at 7,000 $\mathrm{xg}$ for $10 \mathrm{~min}$ at $4^{\circ} \mathrm{C}$ and the resulting pellets were collected as the mitochondrial fraction.

Protein concentrations were determined using a BCA protein assay kit (23225; Thermo Fisher Scientific, Inc.). Equal amounts of protein $(30 \mu \mathrm{g})$ were boiled for $10 \mathrm{~min}$ and resolved by $7.5-12 \%$ SDS-PAGE. The resolved proteins were then transferred to polyvinylidene difluoride membranes (Millipore Corp., Billerica, MA, USA). The membranes were blocked by incubation with $1 \%$ bovine serum albumin (BSA; GenDepot, Inc.) in a buffer of $10 \mathrm{mM}$ Tris- $\mathrm{HCl}(\mathrm{pH} 7.5)$ containing $150 \mathrm{mM} \mathrm{NaCl}$ and $0.1 \%$ Tween-20 (TBS-T) at room temperature for $1 \mathrm{~h}$, and then incubated with specific primary antibodies (Santa Cruz Biotechnology, Inc., Dallas, TX, USA) for $3 \mathrm{~h}$. The membranes were washed three times with TBS-T and incubated for $2 \mathrm{~h}$ with the appropriate horseradish peroxidase (HRP)-conjugated goat anti-rabbit, goat anti-mouse or rabbit anti-goat secondary antibody (Santa Cruz Biotechnology, Inc.) diluted at 1:10,000 in TBS-T and 1\% BSA. The respective proteins were detected using the chemiluminescent substrate (K-12045; Advansta, Menlo Park, CA, USA) and visualized on a GeneSys imaging system (SynGene Synoptics, Ltd., London, UK). The following primary antibodies were used: Anti-B-cell lymphoma-2 [Bcl-2; cat. no. sc-492; anti-rabbit immunoglobulin $(\mathrm{Ig}) \mathrm{G}]$, anti-Bcl-2-associated X protein (Bax; cat. no. sc-493; anti-rabbit 
$\operatorname{IgG}$ ), anti-caspase-3 (cat. no. sc-7148; anti-rabbit $\operatorname{IgG}$ ), anti-cytochrome $c$ (cat. no. sc-7159; anti-rabbit IgG), anti-NF-кB (cat. no. sc-7151; anti-rabbit IgG), anti-Nrf2 (cat. no. sc-722; anti-rabbit $\operatorname{IgG}$ ), anti-phospho (p)-p38 (cat. no. sc-7973, anti-mouse $\mathrm{IgG}$ ), anti-p38 (cat. no. sc-7149; anti-rabbit $\operatorname{IgG}$ ), anti-p-mitogen-activated protein kinase (p-MAPK; cat. no. sc-7383; anti-mouse IgG), anti-MAPK (cat. no. sc-94; anti-rabbit $\mathrm{IgG}$ ), anti-p-c-Jun $\mathrm{N}$-terminal kinase (JNK; cat. no. sc-6254; anti-mouse IgG), anti-JNK (cat. no. sc-7345; anti-mouse $\operatorname{IgG}$ ), anti-nitrotyrosine (cat. no. sc-32757; anti-mouse $\mathrm{IgG}$ ), anti-histone H3 (cat. no. sc-374669; anti-mouse IgG), anti-heat shock protein 60 (cat. no. sc-59567; anti-mouse IgG) and anti- $\beta$-actin (cat. no. sc-4778; anti-mouse IgG). The secondary antibodies used were HRP-conjugated anti-mouse IgG (cat. no. sc-2031; Santa Cruz Biotechnology, Inc.), anti-rabbit IgG (cat. no. A-0545; Sigma-Aldrich Co., St. Louis, MO, USA) and anti-goat IgG (cat. no. A50-101P; Bethyl Laboratories, Inc., Montgomery, TX, USA).

Reactive oxygen species (ROS) content assay. The relative levels of ROS were determined using a 2',7'-dichlorofluorescin diacetate (DCF-DA) fluorescence assay. Cells were pretreated with PYP and incubated in Hank's Balanced Salt Solution (HBSS; pH 7.4) containing $20 \mu \mathrm{M}$ DCF-DA (Sigma-Aldrich; Merck KGaA) at $37^{\circ} \mathrm{C}$ for $1 \mathrm{~h}$. Cells were then washed with HBSS and treated with $20 \mu \mathrm{M}$ cisplatin in HBSS for $8 \mathrm{~h}$. DCF-DA fluorescence intensity was determined using a SpectraMax ${ }^{\circledR}$ M2 Multimode Microplate Reader (Molecular Devices, Sunnyvale, CA, USA) with an excitation wavelength of $485 \mathrm{~nm}$ and an emission wavelength of $524 \mathrm{~nm}$.

Animal care and PYP treatments. A total of 21 male C57BL/6 mice $(22 \pm 2 \mathrm{~g})$ were purchased from Samtako Bio Korea Co. (Gyeonggi-do, Korea). They were fed a standard commercial diet and housed at an ambient temperature of $20-22^{\circ} \mathrm{C}$ with a relative humidity of $50 \pm 5 \%$ under a 12 -h light/dark cycle in a specific pathogen-free facility. Food and water were provided ad libitum. Mice (age, 8 weeks) were divided into three treatment groups (n=7/group): Control group, cisplatin group and PYP + cisplatin group. The mice in the cisplatin group received cisplatin (20 mg/kg body weight) in 5\% dimethyl sulfoxide (v/v) as a single intraperitoneal injection. The mice of the PYP + cisplatin group were orally administered PYP (100 mg/kg body weight) for 7 days. At $72 \mathrm{~h}$ after cisplatin injection, mice were sacrificed and the kidney tissues and blood samples were collected for the subsequent experiments.

The animal protocol of present study was approved by the Institutional Animal Care and Use Committee of Pukyong National University (Busan, Korea; approval no. 2016-14).

Renal function monitoring. For the renal function analysis, serum was separated from blood and stored at $-80^{\circ} \mathrm{C}$ until use. Serum creatinine and blood urea nitrogen (BUN) levels were measured using an assay kit (BioVision, Milpitas, CA, USA) according to the manufacturer's instructions.

Reverse transcription-polymerase chain reaction (RT-PCR). Total RNA from each sample was extracted using TRIzol reagent (Invitrogen; Thermo Fisher Scientific, Inc.). Total RNA $(1 \mu \mathrm{g})$ was subjected to first-strand complementary (c)DNA synthesis using a Reverse Transcriptase Premix kit (IP25084; Intron Biotechnology, Inc., Gyeonggi-do, Korea). PCR amplification of the cDNA products was performed with $2 \mathrm{X}$ TOPsimple ${ }^{\mathrm{TM}}$ DyeMIX (aliquot)-nTag (P561T; Enzynomics, Daejeon, Korea) and primer pairs. The PCR primer sequences for the tested genes were as follows: Tumor necrosis factor- $\alpha$ (TNF- $\alpha$ ) forward, 5'-TGC ACC ACA GTT TAA ACC CA-3' and reverse, 5'-GAC TCCT TCA GGT GCT CAG G-3' $(42,43)$; interleukin-6 (IL-6) forward, 5'-AGG AGA CTT GCC TGG TGA AA-3' and reverse, 5'-CAG GGG T GG TTA TTG CAT CT-3' (43); IL-1 $\beta$ forward, 5'-CTG TCC TGC GTG TTG AAA GA-3' and reverse, 5'-TTC TGC TTG AGA GGT GCT GA-3' (43); monocyte chemoattractant protein-1 (MCP-1) forward, 5'-ACT GAA GCT CGC ACT CTC-3' and reverse, 5'-GAG TGA GGT GTT GGG TTC-3'; glyceraldehyde 3-phosphate dehydrogenase (GAPDH) forward, 5'-CAG CCG AGC CAC ATC G-3' and reverse, 5'-TGA GGC TGT TGT CAT ACT TCT C-3'. Reaction mixtures were incubated for and initial denaturation at $95^{\circ} \mathrm{C}$ for $3 \mathrm{~min}$ followed by 30 cycles of $95^{\circ} \mathrm{C}$ for $30 \mathrm{sec}, 60^{\circ} \mathrm{C}$ for $45 \mathrm{sec}$ and $72^{\circ} \mathrm{C}$ for $60 \mathrm{sec}$. The amplified products were normalized using GAPDH as an internal control, and separated using 1\% agarose gel electrophoresis. The densitometry was determined using GeneTools software, version 4.03 (Syngene, Cambridge, UK).

Statistical analysis. Values are expressed as the mean \pm standard deviation (SD) of three independent experiments and seven animals. Significant differences among multiple mean values were assessed by one-way analysis of variance followed by the Bonferrori multiple comparison test using GraphPad Prim 6 (GraphPad Software Inc., La Jolla, CA, USA). P<0.05 was considered to indicate a statistically significant difference.

\section{Results}

Preparation of PYP. PYP was isolated from the aqueous extract of $P$. yezoensis by simple fractionation based on ammonium sulfate precipitation. After ultrafiltration and lyophilization of the pooled desalted PYP, a total of $120 \mathrm{mg}$ of PYP was obtained from $5 \mathrm{~g}$ of dried $P$. yezoensis. SDS-PAGE analysis revealed six major bands and proteins of 25-37 $\mathrm{kDa}$ in size accounted for $50 \%$ of the total protein (Fig. 1A).

Cisplatin decreases the viability of the HK2 renal cell line. Renal proximal tubular epithelial cells are the major targets of toxic drugs such as cisplatin (8). To assess the effects of cisplatin on cell viability, HK2 cells were incubated with various concentrations $(0-40 \mu \mathrm{M})$ of cisplatin. The cisplatin treatment significantly decreased the viability of HK2 cells in a concentration-dependent manner (Fig. 1B). After incubation with $0,10,20$ and $40 \mu \mathrm{M}$ cisplatin for $24 \mathrm{~h}$, cell viability was significantly reduced to $100.0 \pm 5.00,83.0 \pm 7.21,72.0 \pm 7.00$ and $61.7 \pm 7.02 \%$, respectively. In addition, to examine the effects of cisplatin at the microscopic level, HK2 cells were treated with various concentrations of cisplatin and assessed under a microscope, indicating that the cell viability was decreased in a cisplatin concentration-dependent manner (Fig. 1C).

PYP protects HK2 cells against cisplatin-induced cytotoxicity. The effects of PYP on cisplatin-induced decreases in cell viability were then assessed. HK2 cells were incubated with 

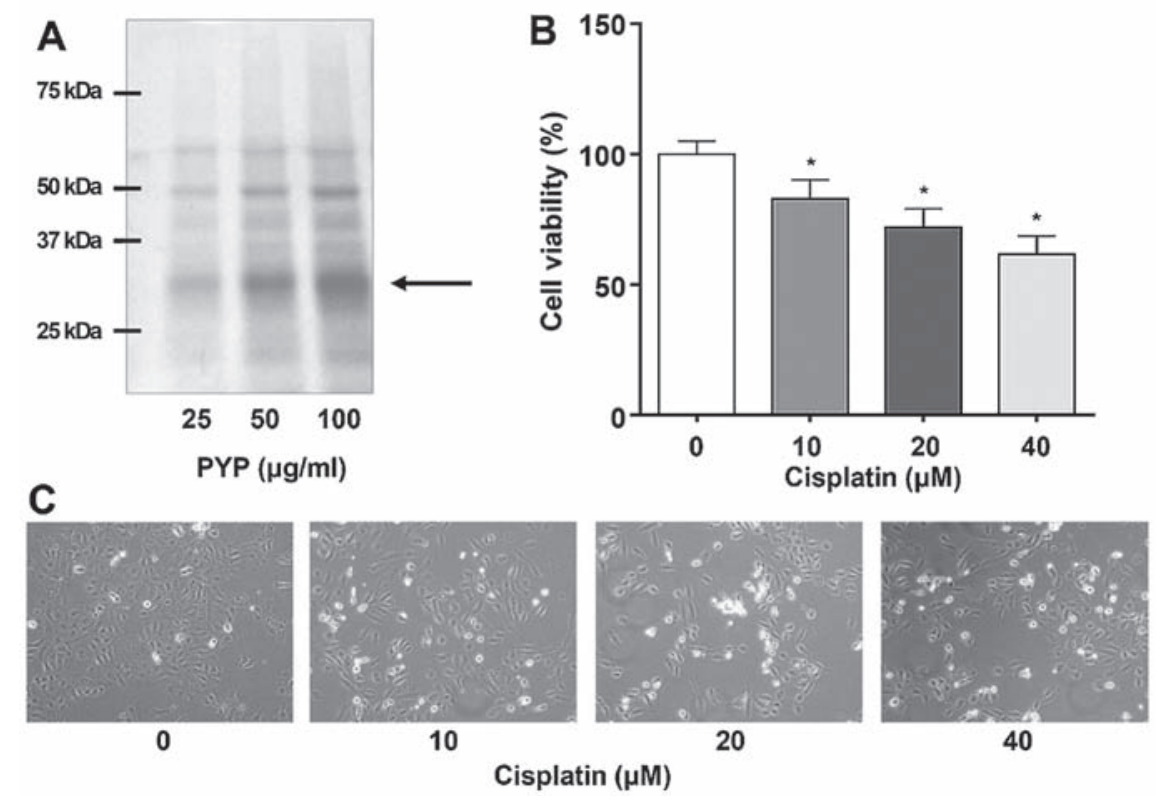

Figure 1. Cisplatin inhibits the viability of HK2 cells. (A) The extracted PYP fraction exhibited six major bands in the SDS-PAGE analysis (marker units in $\mathrm{kDa}$ ). (B) HK2 cells were incubated with various concentrations of cisplatin for $24 \mathrm{~h}$. Cell viability was assessed using a CytoX assay kit. (C) HK2 cells were incubated with various concentrations of cisplatin for $24 \mathrm{~h}$. Cell morphological changes were observed under a light microscope (magnification, $\mathrm{x} 200$ ). Values are expressed as the mean \pm standard deviation of three independent experiments. Data were analyzed using one-way analysis of variance. ${ }^{*} \mathrm{P}<0.05$ vs. control. PYP, protein of P. yezoensis; SDS-PAGE, sodium dodecyl sulfate-polyacrylamide gel electrophoresis.

$20 \mu \mathrm{M}$ cisplatin for $8 \mathrm{~h}$ following pretreatment with various concentrations of PYP for $24 \mathrm{~h}$. As presented in Fig. 2A, PYP treatment increased the viability of cisplatin-induced HK2 cells in a concentration-dependent manner (Fig. 2A). The cell viability in the group treated with $20 \mu \mathrm{M}$ cisplatin was $64.0 \pm 3.61 \%$ of that in the control group. However, treatment with 25,50 and $100 \mu \mathrm{g} / \mathrm{ml}$ of PYP significantly increased the cell viability in a concentration-dependent manner to $71.3 \pm 3.21,81.7 \pm 3.79$ and $87.7 \pm 2.52 \%$, respectively, of that in the control group.

Next, the effects of PYP treatment on the translocation of cytochrome $c$ in cisplatin-treated HK2 cells were examined. As presented in Fig. 2B, treatment with cisplatin alone increased the release of cytochrome $c$ from the mitochondria into the cytosolic fraction. However, treatment with PYP decreased the cisplatin-induced release of cytochrome $c$ from the mitochondria to the cytosol. Furthermore, treatment with cisplatin alone increased Bax and caspase- 3 expression, and decreased Bcl-2 expression (Fig. 2C), which was inhibited by $\mathrm{PYP}$ in a concentration-dependent manner.

$P Y P$ inhibits $N F-\kappa B$ activation and restores Nrf2 inactivation in cisplatin-treated HK2 cells. Drugs such as cisplatin may cause AKI, which may be associated with increases of ROS or inflammation. AKI is also associated with transcription factors such as $N F-\kappa B$ and Nrf2. NF- $\mathrm{NB}$ is a key transcription factor in renal inflammation and the oxidative stress response. $\mathrm{NF}-\kappa \mathrm{B}$ regulates the inflammatory response by regulating anti- or pro-cytokine expression. Therefore, the effects of PYP treatment on $\mathrm{NF}-\kappa \mathrm{B}$ translocation in cisplatin-treated HK2 cells were examined by western blot analysis. As presented in Fig. 3A, cisplatin increased the levels of nuclear NF- $\kappa \mathrm{B}$ p65 and decreased the levels of cytosolic NF- $\mathrm{B}$ p65, which was inhibited by PYP. Nrf2 inhibits cell damage by reducing intracellular ROS production. As displayed in Fig. 3B, cisplatin decreased the content of Nrf2 in the nuclear fraction and increased that in the cytosolic fraction, which was inhibited by PYP treatment.

PYP decreases cisplatin-induced oxidative stress by downregulating the p38/MAPK/JNK pathway. To determine the role of ROS production in the cytoprotective effects of PYP, its effects on ROS production and nitrotyrosine expression in cisplatin-treated HK2 cells were examined. HK2 cells were incubated with $20 \mu \mathrm{M}$ cisplatin for $8 \mathrm{~h}$ after pretreatment with PYP, and intracellular ROS production and nitrotyrosine expression levels were then determined by measuring the fluorescence intensity of DCF-DA and western blot analysis, respectively. While ROS were significantly induced in the cisplatin treatment group, they were significantly and concentration-dependently reduced in the groups pretreated with PYP (Fig. 4A). Nitrotyrosine expression was also significantly reduced in the presence of PYP in a concentration-dependent manner (Fig. 4B). The phosphorylation levels of MAPK proteins including p38, ERK and JNK are correlated with oxidative stress. In the present study, it was determined that the phosphorylation levels of p38, MAPK and JNK were increased in the cisplatin treatment group, which was inhibited in the presence of PYP in a concentration-dependent manner (Fig. 4C and D).

PYP treatment improves cisplatin-induced renal dysfunction in vivo. The renoprotective role of PYP against cisplatin-induced AKI was then examined in vivo. BUN and creatinine levels of cisplatin/PYP-treated mice were assessed to evaluate kidney function. As presented in Fig. 5, the levels of BUN were significantly higher in the cisplatin group $(148.1 \pm 1.01 \mathrm{mg} / \mathrm{dl})$ compared with those in the control group 


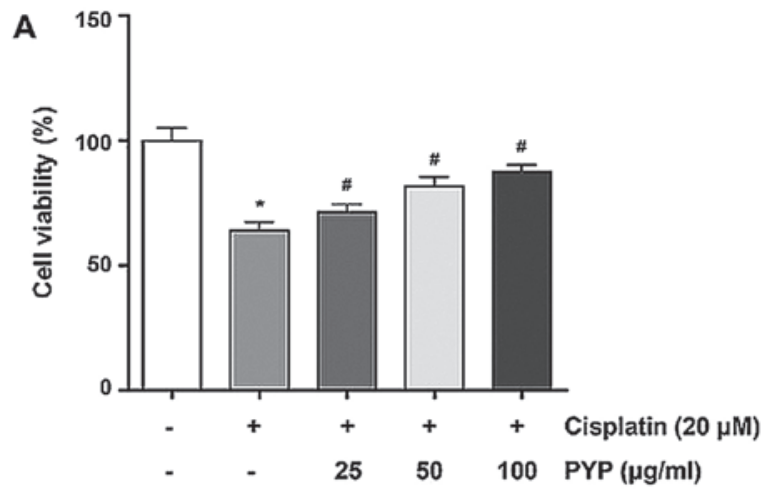

B

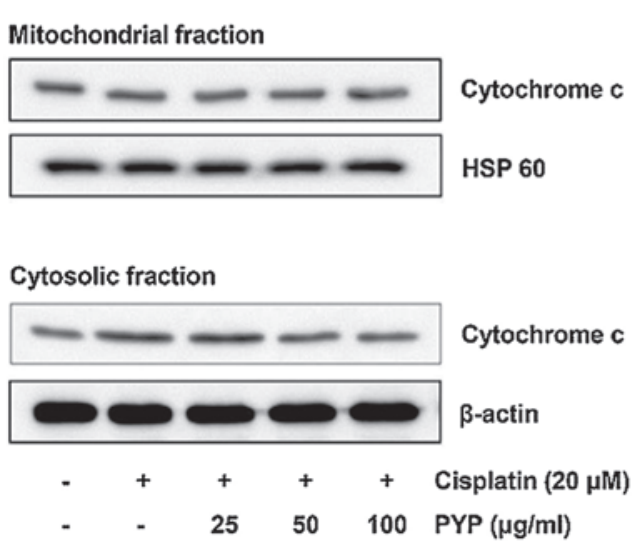

C

Figure 2. PYP treatment inhibits cisplatin-induced cell death through cytochrome $c$ translocation and apoptotic signaling in HK2 cells. (A) HK2 cells were incubated with various concentration of cisplatin or PYP for $24 \mathrm{~h}$. Cell viability was measured using CytoX assay kit. (B) HK2 cells were incubated with $20 \mu \mathrm{M}$ cisplatin and various concentrations of PYP for $24 \mathrm{~h}$. The protein levels of cytochrome $c$ in mitochondrial and cytosolic fractions were examined by western blot analysis. (C) Protein levels of Bax, Bcl-2 and caspase-3 were examined by western blot analysis. Values are expressed as the mean \pm standard deviation of three independent experiments. Data were analyzed using one-way analysis of variance. ${ }^{*} \mathrm{P}<0.05$ vs. control; ${ }^{\mathrm{P}} \mathrm{P}<0.05$ vs. cisplatin-treated groups. $\mathrm{PYP}$, protein of P. yezoensis; Bcl-2, B-cell lymphoma 2; Bax, Bcl-2-associated X protein.

A

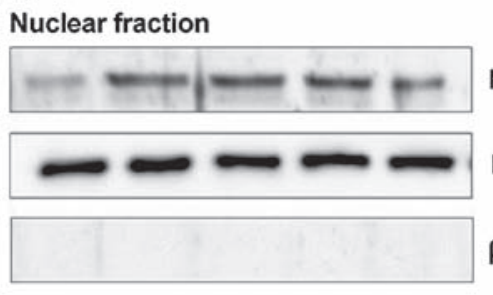

NF-KB

Histone $\mathrm{H3}$

$\beta$-actin

crovole thataton

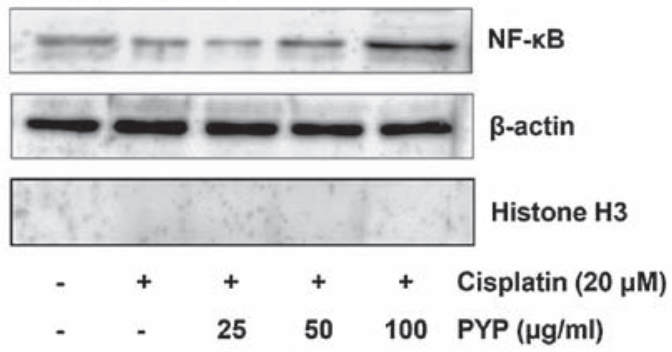

B

Nuclear fraction

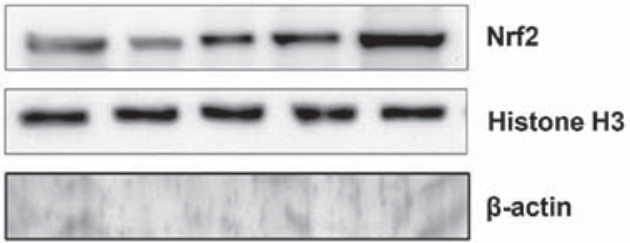

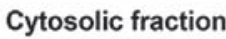

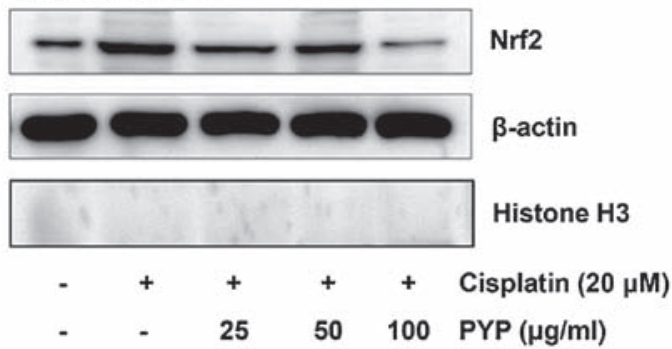

Figure 3. PYP treatment blocks NF- $\mathrm{B}$ activation and restores Nrf2 inactivation in cisplatin-treated HK2 cells. HK2 cells were incubated with various concentrations of $20 \mu \mathrm{M}$ cisplatin and PYP for $24 \mathrm{~h}$. The protein levels of (A) NF- $\kappa \mathrm{B}$ and (B) Nrf2 in the nuclear and the cytosolic fraction were examined by western blot analysis. The bands were normalized to $\beta$-actin or histone H3 as internal control. NF, nuclear factor; Nrf2, NF erythroid 2-related factor 2; PYP, protein of P. yezoensis.

$(21.6 \pm 1.74 \mathrm{mg} / \mathrm{dl})$. However, in the PYP + cisplatin group, the cisplatin-associated increase in BUN was significantly inhibited by PYP $(84.2 \pm 2.07 \mathrm{mg} / \mathrm{dl})$. In addition, as presented in Fig. 5, the levels of serum creatinine in the cisplatin group 
A

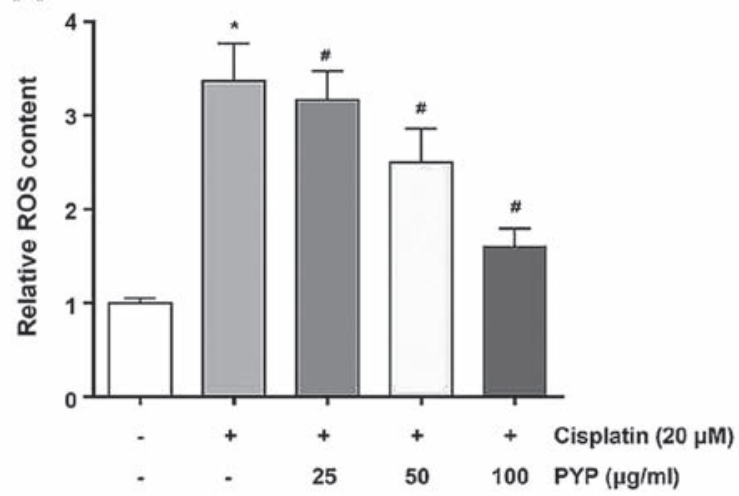

B

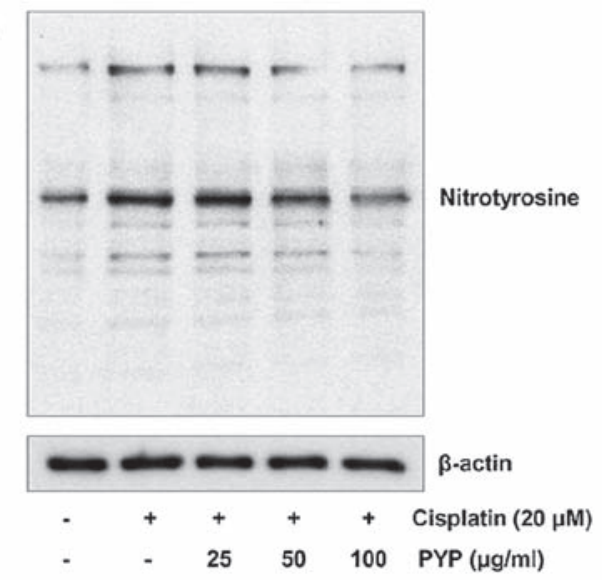

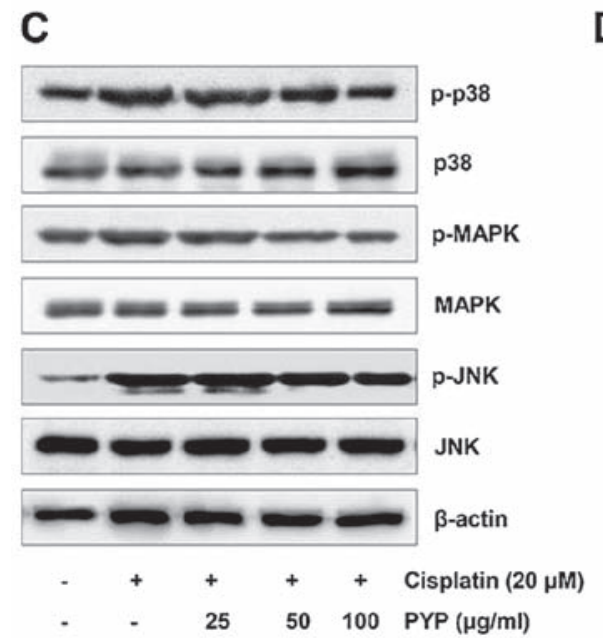
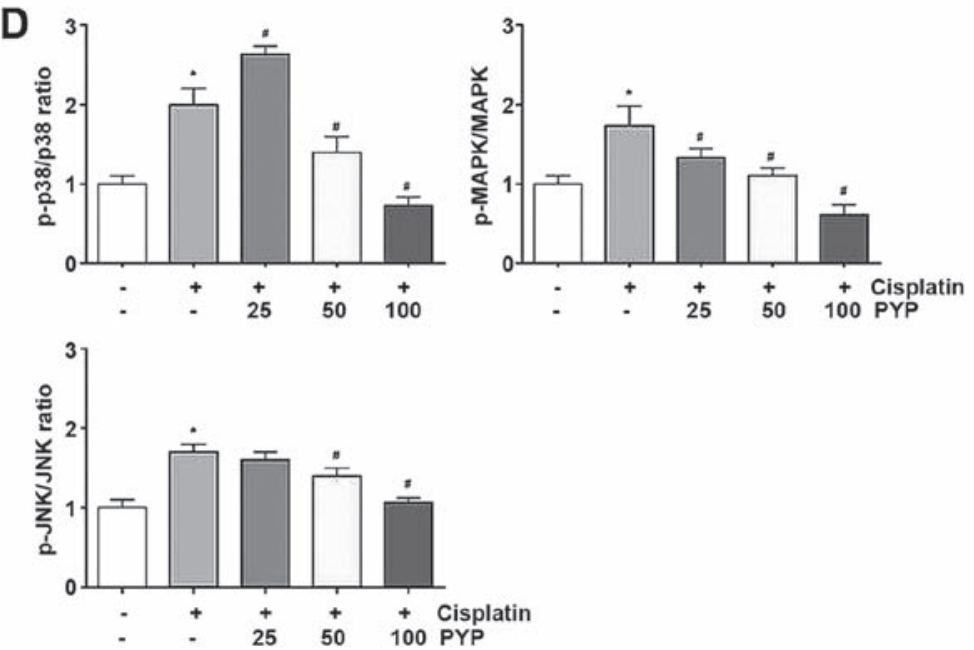

Figure 4. PYP treatment inhibits cisplatin-induced oxidative stress by downregulating the p38/MAPK/JNK pathway in HK2 cells. (A) HK2 cells were incubated with $20 \mu \mathrm{M}$ cisplatin for $8 \mathrm{~h}$ and various concentrations of PYP for $24 \mathrm{~h}$. The cellular ROS content was analyzed using a 2',7'-dichlorofluorescin diacetate fluorescence assay. (B and C) The protein levels of (B) nitrotyrosine and (C) p38, MAPK and JNK were examined by western blot analysis. (D) Bands were normalized to $\beta$-actin as an internal control, and the phosphorylated vs. total protein ratio is graphed. Values are expressed as the mean \pm standard deviation of three independent experiments. Data were analyzed using one-way analysis of variance. ${ }^{~} \mathrm{P}<0.05$ vs. control; " $\mathrm{P}<0.05$ vs. cisplatin-treated group. MAPK, mitogen-activated protein kinase; p-JNK, phosphorylated c-Jun N-terminal kinase; ROS, reactive oxygen species; PYP, protein of $P$. yezoensis.

$(1.20 \pm 0.12 \mathrm{mg} / \mathrm{dl})$ were higher than those the control group $(0.32 \pm 0.15 \mathrm{mg} / \mathrm{dl})$. PYP significantly prevented the change in serum creatinine induced by cisplatin, resulting in serum creatinine levels of $0.69 \pm 0.11 \mathrm{mg} / \mathrm{dl}$.

PYP treatment reduces inflammatory gene expression in cisplatin-induced AKI. Next, the mRNA expression levels of various cytokines associated with the inflammatory process were assessed in the kidney tissues of the experimental animals. The mRNA levels of IL-6, IL-1 $\beta$, TNF- $\alpha$ and MCP- 1 in the cisplatin group were significantly higher than those in the control group (Fig. 6). By contrast, the mRNA expression levels of IL-6, IL-1 $\beta$, TNF- $\alpha$ and MCP-1 in the PYP + cisplatin group were significantly decreased compared with those in the cisplatin group $(1.4 \pm 0.09$ vs. $2.7 \pm 0.41$-fold, $1.80 \pm 0.07$ vs. $2.6 \pm 0.11$-fold, $1.5 \pm 0.06$ vs. $2.7 \pm 0.06$-fold and $1.6 \pm 0.21$ vs. $2.8 \pm 0.19$-fold of those in the control group, respectively).

\section{Discussion}

AKI is defined as a rapid loss of renal function due to kidney damage, which results in retention of the nitrogenous and non-nitrogenous waste products normally excreted by the kidney $(44,45)$. AKI is common among hospitalized patients; indeed, its incidence has increased over the past few decades, possibly due to the aging population and an increased frequency of comorbidities (46). AKI is associated with increased mortality and a greater risk of chronic kidney disease, as well as end-stage renal disease (47). Recognizing and treating AKI as early as possible may prevent kidney damage. Therefore, understanding the key regulatory factors in drug-induced kidney dysfunction is critical.

Cisplatin is one of the most widely used chemotherapeutic drugs for the treatment of various malignancies such as bladder cancer, lung cancer, breast cancer and malignant melanoma (48-50). Cisplatin is a front-line chemotherapeutic agent for solid tumors, and AKI is an important side effect, as is a chronic decline in kidney function. Renal tubular cells are particularly sensitive to cisplatin treatment. Cisplatin-induced renal cell death involves the activation of multiple pathways, including the intrinsic and extrinsic apoptotic pathways, oxidative stress and inflammatory responses (15). Unfortunately, numerous of these pathways are also involved in the desirable cytotoxic effects of cisplatin on tumor cells $(51,52)$. Therefore, development of an effective method of preventing cisplatin-induced AKI is of critical importance. In the present study, a novel investigation 

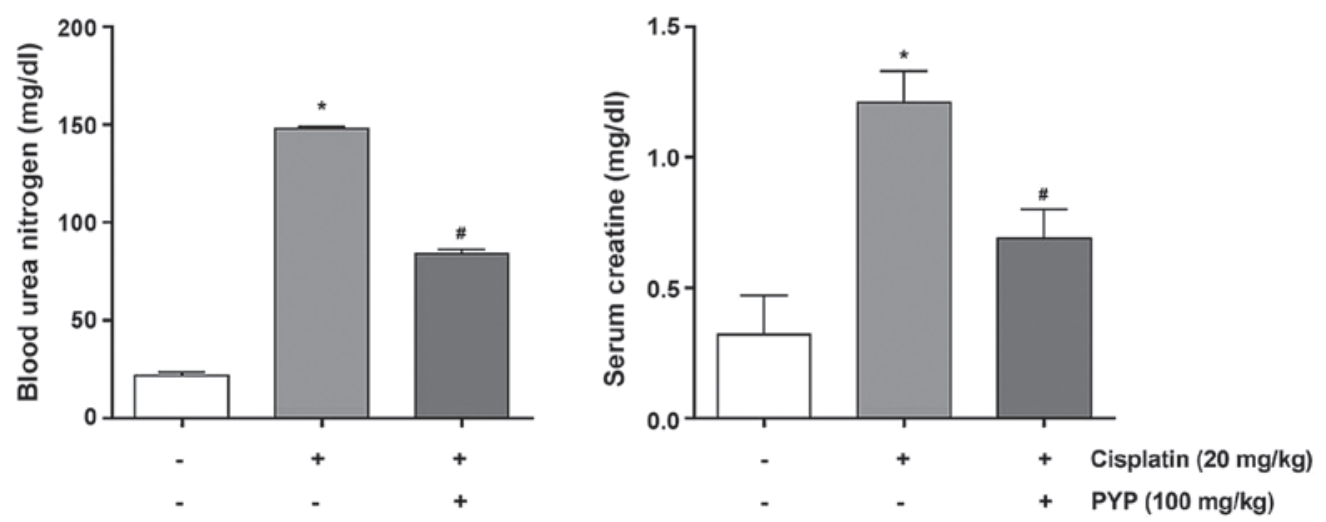

Figure 5. PYP treatment protects against cisplatin-induced changes in BUN and creatinine levels associated with renal injury in C57BL/6 mice. The mice were sacrificed $72 \mathrm{~h}$ after cisplatin injection and the blood was collected. The levels of BUN and serum creatinine were examined by using an assay kit. Values are expressed as the mean \pm standard deviation of three independent experiments. Data were analyzed using one-way analysis of variance. "P<0.05 vs. control; ${ }^{\text {"}} \mathrm{P}<0.05$ vs. cisplatin-treated group. BUN, blood urea nitrogen; PYP, protein of P. yezoensis.
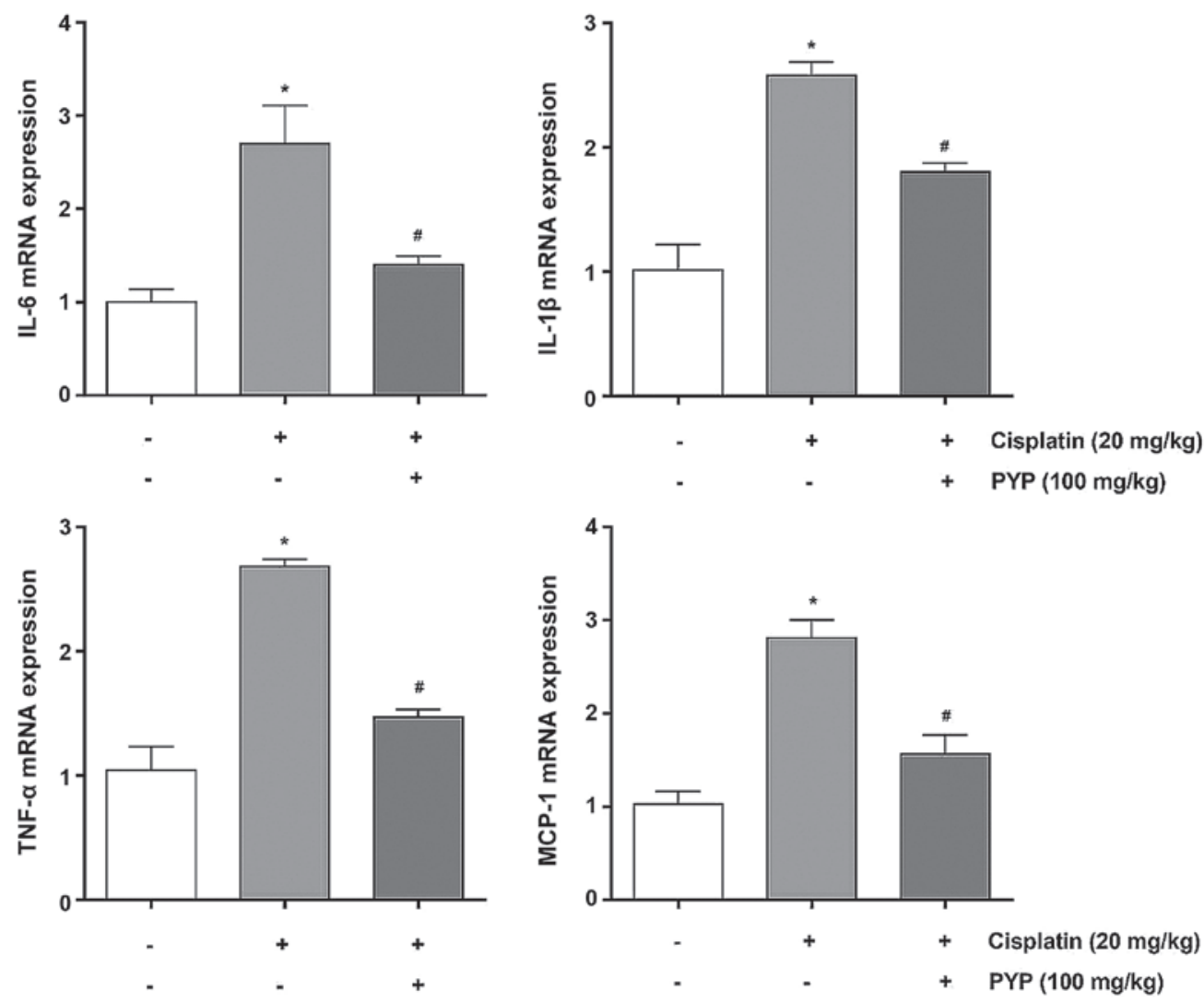

Figure 6. PYP treatment reduces inflammatory gene expression in C57BL/6 mice with cisplatin-induced renal injury. The mice were sacrificed $72 \mathrm{~h}$ after cisplatin injection and kidney tissues were collected. The mRNA expression levels of IL-6, IL-1 $\beta$, TNF- $\alpha$ and MCP-1 were examined by using reverse transcription-quantitative polymerase chain reaction analysis. Values are expressed as the mean \pm standard deviation of three independent experiments. Data were analyzed using one-way analysis of variance. ${ }^{*} \mathrm{P}<0.05$ vs. control; ${ }^{~} \mathrm{P}<0.05$ vs. cisplatin-treated group. IL, interleukin; TNF, tumor necrosis factor; $\mathrm{MCP}$, monocyte chemoattractant protein; PYP, protein of P. yezoensis.

of the protective effects of PYP, extracted from P. yezoensis, on cisplatin-induced cell death in human renal proximal tubular epithelial cells and an animal model was pursued. The results indicated that PYP inhibited the cisplatin-induced death of HK2 cells, and reduced AKI-associated clinical parameters (Nrf2 and NF- $\mathrm{kB}$ ) and inflammatory biomarkers (IL-6, IL-1 $\beta$, TNF- $\alpha$ and MCP-1) in vivo.

In the present study, the effects of PYP on the cisplatin-induced reduction in HK2 cell viability were assessed.PYP treatment resulted in a recovery of cell viability in a concentration-dependent manner (Fig. 2A). The cisplatin-induced cell death was ameliorated by PYP treatment, which was also in parallel with the recovery of changes in the expression levels of various apoptotic proteins. The cisplatin-treated cells exhibited increased cytochrome $c$ release from the mitochondria to the cytosol, as well as increased Bax and caspase-3. However, compared with the cisplatin-treated group, pretreatment with PYP resulted in decreased cytochrome $c$ release from the 
mitochondria to the cytosol, decreased Bax and caspase-3 expression. In addition, western blot analysis revealed that cisplatin treatment significantly reduced Bcl-2 expression: The protein levels of Bcl-2 were decreased by $\sim 40 \%$ following treatment with $20 \mu \mathrm{M}$ cisplatin, which was inhibited by pretreatment with PYP. These results suggested that PYP protects HK2 cells against cisplatin-induced cell death.

The NF- $\mathrm{kB}$ pathway involves an important family of transcription factors, which control the expression of cytokines, cell adhesion molecules, growth factors and also apoptosis, proliferation, differentiation and survival (53-55). Of note, NF-кB activation has been observed in renal tubular cells treated with cisplatin $(56,57)$, and the activation of NF- $\mathrm{kB}$ in kidneys has been demonstrated in cisplatin-induced AKI $(58,59)$. PYP ameliorated cisplatin-induced nephrotoxicity in HK2 cells by reducing NF- $\mathrm{KB}$ activation and inducing Nrf2 activation to inhibit cisplatin-induced cell death. In addition, an inverse correlation in expression was detected between $\mathrm{Nrf} 2$ and NF- $\kappa B$. This suggested that PYP blocked NF- $\kappa B$ activation and restored Nrf2 inactivation in cisplatin-treated HK2 cells.

Oxidative stress also has a critical role in the pathogenesis of cisplatin-induced nephrotoxicity (17). ROS-induced cell death has been reported in renal proximal tubular epithelial cells, and ROS promoted cisplatin-induced renal failure $(15,17)$. The effects of various functional substances derived from seaweeds on oxidative stress and $\mathrm{Nrf} 2 / \mathrm{Heme}$ oxygenase-1 activation have been evaluated $(17,43)$. In the present study, PYP treatment suppressed cisplatin-induced p38/MAPK/JNK activation. This was mediated by a reduction in ROS content. These results indicate that PYP decreases cisplatin-induced oxidative stress by downregulating the p38/MAPK/JNK pathway. These results also indicate that PYP may suppress the cisplatin-induced death of HK2 cells by ameliorating ROS-mediated oxidative stress.

PYP may protect renal tissue from cisplatin-induced damage without reducing the tumoricidal activity of the drug, which involves enzymatic activation and subsequent regulation of the levels of intracellular metabolites and signaling molecules. Thus, strategies that attenuate cisplatin-induced renal injury may have the unintended consequence of reducing its antitumor activity. Preventive strategies must therefore be designed in such a way that this deleterious consequence is avoided.

Although the molecular mechanisms underlying cisplatin-induced nephrotoxicity are complex and remain to be fully elucidated, induction of oxidative damage, renal tubular cell death and activation of inflammatory-related pathways have been demonstrated in the kidneys of cisplatin-treated animals. Cisplatin application enhances oxidative stress in kidney tissue, demonstrated by increased levels of free radicals, structural modifications of proteins and lipid peroxidation. Cisplatin generates reactive free radicals, which interact with and modify cellular components, leading to cell death. Cisplatin-induced ROS generation in renal tubular cells activates the expression of NF- $\mathrm{kB}$ and pro-inflammatory cytokines and chemokines. In the gentamicin animal model, increased MAPK and NF- $\mathrm{KB}$ activation as well as increased plasma creatinine levels were observed in the renal cortex of gentamicin-injected rats compared with the control group (60). These results indicated that inhibiting NF- $\kappa \mathrm{B}$ activation attenuates gentamicin-induced kidney dysfunction.
Oxidative stress in kidneys is considered to be a major cause of renal injury and inflammation, giving rise to a variety of pathological disorders. Several studies have demonstrated that excessive ROS production in AKI tissues triggers cell death, and antioxidant agents have been used to prevent associated increases in lipid peroxidation, resulting in reduced kidney injury $(61,62)$.

In the present study, cellular ROS production was attenuated by PYP treatment, that cisplatin-induced Nrf2 activation through its antioxidant effects. These results suggested that the renoprotective effect of PYP may be attributable to its free radical-scavenging and antioxidant activities. In addition, the present results revealed that PYP treatment decreased nitrotyrosine expression and suppressed NF- $\mathrm{KB}$ activation in the presence of cisplatin. The predominant mechanism underlying kidney dysfunction in response to cisplatin exposure is downregulation of the NF- $\mathrm{kB} / \mathrm{MAPK}$ pathway. These results suggested a novel mechanism of cisplatin-induced nephrotoxicity through metabolic regulation by PYP. Therefore, administration of PYP or dietary supplementation of seaweed may represent a promising strategy to reduce this side effect of cisplatin treatment.

Based on these results, experimental mice were divided into three groups (control, cisplatin, PYP + cisplatin) and the effects of PYP were evaluated in this mouse model of cisplatin-induced AKI. Renal function was assessed by measuring the concentration of BUN and creatinine. The results indicated that BUN and serum creatinine were lower in the PYP + cisplatin group than in the cisplatin group. In addition, the mRNA expression levels of inflammatory factors in kidney tissues were examined. The mRNA expression levels of IL-6, IL-1 $1 \beta$, TNF- $\alpha$ and MCP-1 in the PYP + cisplatin group were lower than those in the cisplatin group. The levels of inflammatory factors in kidney tissues were examined, and were confirmed to be consistent with the results obtained in HK2 cells. For instance, the expression of p38 and JNK was lower in the PYP + cisplatin group than that in the cisplatin group (data not shown). Therefore, PYP appears to prevent cisplatin-induced nephrotoxicity by regulating the expression of inflammatory factors in vivo.

The present results demonstrated, for the first time, to the best of our knowledge, the potential therapeutic effect of the seaweed $P$. yezoensis against cisplatin-induced nephrotoxicity in vitro and in vivo, which was mediated by downregulation of the MAPK and NF- $\kappa B$ pathways. The present results suggested that $P$. yezoensis is a valuable source of potential anti-nephrotoxic proteins that act by inhibiting cell death and kidney dysfunction induced by cisplatin. Therefore, further research to isolate and identify bioactive functional proteins from P. yezoensis is warranted.

In conclusion, the present study demonstrated that PYP exerted protective effects against cisplatin-induced AKI, possibly by regulating the MAPK/NF- $\kappa$ B pathways. These effects substantially contributed to the elimination of excessive oxidative stress and to protected against cell death.

\section{Acknowledgements}

This study was supported by the Basic Science Research Program through the National Research Foundation of Korea funded by the Ministry of Education (grant no. 2012R1A6A1028677). 


\section{References}

1. Kowald A and Kirkwood TB: Can aging be programmed? A critical literature review. Aging Cell 15: 986-998, 2016.

2. Vaiserman AM, Lushchak OV and Koliada AK: Anti-aging pharmacology: Promises and pitfalls. Ageing Res Rev 31: 9-35, 2016.

3. Wen J, Zeng M, Shu Y, Guo D, Sun Y, Guo Z, Wang Y, Liu Z Zhou $\mathrm{H}$ and Zhang W: Aging increases the susceptibility of cisplatin-induced nephrotoxicity. Age (Dordr) 37: 112, 2015.

4. Wang X, Bonventre JV and Parrish AR: The aging kidney: Increased susceptibility to nephrotoxicity. Int J Mol Sci 15 : 15358-15376, 2014.

5. Anand S, Johansen KL and Kurella Tamura M: Aging and chronic kidney disease: The impact on physical function and cognition. J Gerontol A Biol Sci Med Sci 69: 315-322, 2014.

6. He YH, Pu SY, Xiao FH, Chen XQ, Yan DJ, Liu YW, Lin R, Liao XP, Yu Q, Yang LQ, et al: Improved lipids, diastolic pressure and kidney function are potential contributors to familial longevity: A study on 60 Chinese centenarian families. Sci Rep 6 : 21962, 2016

7. Calvo-Rubio M, Burón MI, López-Lluch G, Navas P, de Cabo R, Ramsey JJ, Villalba JM and González-Reyes JA: Dietary fat composition influences glomerular and proximal convoluted tubule cell structure and autophagic processes in kidneys from calorie-restricted mice. Aging Cell 15: 477-487, 2016.

8. Chevalier RL: The proximal tubule is the primary target of injury and progression of kidney disease: Role of the glomerulotubular junction. Am J Physiol Renal Physiol 311: F145-F161, 2016.

9. Li Z, Sheng Y,Liu C, Li K, Huang X, Huang J and Xu K: Nox4 has a crucial role in uric acid induced oxidative stress and apoptosis in renal tubular cells. Mol Med Rep 13: 4343-4348, 2016.

10. Rogers NM, Stephenson MD, Kitching AR, Horowitz JD and Coates PT: Amelioration of renal ischaemia-reperfusion injury by liposomal delivery of curcumin to renal tubular epithelial and antigen-presenting cells. Br J Pharmacol 166: 194-209, 2012.

11. Li J, Gui Y, Ren J, Liu X, Feng Y, Zeng Z, He W, Yang J and Dai C: Metformin protects against cisplatin-induced tubular cell apoptosis and acute kidney injury via AMPK $\alpha$-regulated autophagy induction. Sci Rep 6: 23975, 2016.

12. Markó L, Vigolo E, Hinze C, Park JK, Roël G, Balogh A, Choi M, Wübken A, Cording J, Blasig IE, et al: Tubular epithelia NF- $\kappa \mathrm{B}$ activity regulates ischemic AKI. J Am Soc Nephrol 27: 2658-2669, 2016.

13. Stathopoulos GP: Cisplatin: Process and future. J BUON 18: 564-569, 2013.

14. Dugbartey GJ, Bouma HR, Lobb I and Sener A: Hydrogen sulfide: A novel nephroprotectant against cisplatin-induced renal toxicity. Nitric Oxide 57: 15-20, 2016.

15. Herrera-Pérez Z, Gretz N and Dweep H: A comprehensive review on the genetic regulation of cisplatin-induced nephrotoxicity. Curr Genomics 17: 279-293, 2016.

16. El-Naga RN and Mahran YF: Indole-3-carbinol protects against cisplatin-induced acute nephrotoxicity: Role of calcitonin generelated peptide and insulin-like growth factor-1. Sci Rep 6 : 29857, 2016

17. Thongnuanjan P, Soodvilai S, Chatsudthipong V and Soodvilai S: Fenofibrate reduces cisplatin-induced apoptosis of renal proximal tubular cells via inhibition of JNK and p38 pathways. J Toxicol Sci 41: 339-349, 2016.

18. Cunha L and Grenha A: Sulfated seaweed polysaccharides as multifunctional materials in drug delivery applications. Mar Drugs 14: e42, 2016.

19. Grasa-López A, Miliar-García Á, Quevedo-Corona L, PaniaguaCastro N, Escalona-Cardoso G, Reyes-Maldonado E and Jaramillo-Flores ME: Undaria pinnatifida and fucoxanthin ameliorate lipogenesis and markers of both inflammation and cardiovascular dysfunction in an animal model of diet-induced obesity. Mar Drugs 14: e148, 2016.

20. Choi JW,Kim IH,Kim YM,Lee MK and Nam TJ: Pyropia yezoensis glycoprotein regulates antioxidant status and prevents hepatotoxicity in a rat model of D-galactosamine/lipopolysaccharide-induced acute liver failure. Mol Med Rep 13: 3110-3114, 2016

21. Cian RE, Drago SR, de Medina FS and Martínez-Augustin O: Proteins and carbohydrates from red seaweeds: Evidence for beneficial effects on gut function and microbiota. Mar Drugs 13: 5358-5383, 2015

22. Park HK, Kim IH, Kim J and Nam TJ: Induction of apoptosis and the regulation of ErbB signaling by laminarin in HT-29 human colon cancer cells. Int J Mol Med 32: 291-295, 2013.
23. Park HK, Kim IH, Kim J and Nam TJ: Induction of apoptosis by laminarin, regulating the insulin-like growth factor-IR signaling pathways in HT-29 human colon cells. Int J Mol Med 30: 734-738, 2012.

24. Min EY, Kim IH, Lee J, Kim EY, Choi YH and Nam TJ: The effects of fucodian on senescence are controlled by the p16INK4a$\mathrm{pRb}$ and p14Arf-p53 pathways in hepatocellular carcinoma and hepatic cell lines. Int J Oncol 45: 47-56, 2014.

25. Park HY, Han MH, Park C, Jin CY, Kim GY, Choi IW, Kim ND, Nam TJ, Kwon TK and Choi YH: Anti-inflammatory effects of fucoidan through inhibition of NF- $\mathrm{BB}, \mathrm{MAPK}$ and Akt activation in lipopolysaccharide-induced BV2 microglia cells. Food Chem Toxicol 49: 1745-1752, 2011.

26. Go H, Hwang HJ and Nam TJ: A glycoprotein from Laminaria japonica induces apoptosis in HT-29 colon cancer cells. Toxicol In Vitro 24: 1546-1553, 2010.

27. Koyanagi S, Tanigawa N, Nakagawa H, Soeda S and Shimeno H: Oversulfation of fucoidan enhances its anti-angiogenic and antitumor activities. Biochem Pharmacol 65: 173-179, 2003

28. Heo SJ, Park EJ, Lee KW and Jeon YJ: Antioxidant activities of enzymatic extracts from brown seaweeds. Bioresour Technol 96: $1613-1623,2005$.

29. Mhadhebi L, Mhadhebi A, Robert J and Bouraoui A: Antioxidant, anti-inflammatory and antiproliferative effects of aqueous extracts of three mediterranean brown seaweeds of the genus Cystoseira. Iran J Pharm Res 13: 207-220, 2014.

30. Song MY, Ku SK, Kim HJ and Han JS: Low molecular weight fucoidan ameliorating the chronic cisplatin-induced delayed gastrointestinal motility in rats. Food Chem Toxicol 50: 4468-4478, 2012.

31. Easton C, Turner A and Sewell G: An evaluation of the toxicity and bioaccumulation of cisplatin in the marine environment using the macroalga, Ulva lactuca. Environ Pollut 159: 3504-3508, 2011.

32. Choi JW, Kim YM, Park SJ, Kim IH and Nam TJ: Protective effect of Porphyra yezoensis glycoprotein on D-galactosamine induced cytotoxicity in Hepa 1c1c7 cells. Mol Med Rep 11: 3914-3919, 2015.

33. Lee HA, Kim IH and Nam TJ: Bioactive peptide from Pyropia yezoensis and its anti-inflammatory activities. Int J Mol Med 36: 1701-1706, 2015

34. Choi JW, Kim IH, Kim YM, Lee MK, Choi YH and Nam TJ: Protective effect of Pyropia yezoensis glycoprotein on chronic ethanol consumption-induced hepatotoxicity in rats. Mol Med Rep 14: 4881-4886, 2016.

35. Choi JW, Kwon MJ, Kim IH, Kim YM, Lee MK and Nam TJ: Pyropia yezoensis glycoprotein promotes the M1 to M2 macrophage phenotypic switch via the STAT3 and STAT6 transcription factors. Int J Mol Med 38: 666-674, 2016.

36. Ryu J, Park SJ, Kim IH, Choi YH and Nam TJ: Protective effect of porphyra-334 on UVA-induced photoaging in human skin fibroblasts. Int J Mol Med 34: 796-803, 2014.

37. Shin ES, Hwang HJ, Kim IH and Nam TJ: A glycoprotein from Porphyra yezoensis produces anti-inflammatory effects in liposaccharide-stimulated macrophages via the TLR4 signaling pathway. Int J Mol Med 28: 809-815, 2011.

38. Lee MK, Kim IH, Choi YH and Nam TJ: A peptide from Porphyra yezoensis stimulates the proliferation of IEC-6 cells by activating the insulin-like growth factor I receptor signaling pathway. Int J Mol Med 35: 533-538, 2015.

39. Lee MK, Kim IH, Choi YH, Choi JW, Kim YM and Nam TJ: The proliferative effects of Pyropia yezoensis peptide on IEC-6 cells are mediated through the epidermal growth factor receptor signaling pathway. Int J Mol Med 35: 909-914, 2015.

40. Park SJ, Ryu J, Kim IH, Choi YH and Nam TJ: Activation of the mTOR signaling pathway in breast cancer MCF 7 cells by a peptide derived from Porphyra yezoensis. Oncol Rep 33: 19-24, 2015.

41. Park SJ, Ryu J, Kim IH, Choi YH and Nam TJ: Induction of apoptosis by a peptide from Porphyra yezoensis: Regulation of the insulin-like growth factor I receptor signaling pathway in MCF-7 cells. Int J Oncol 45: 1011-1016, 2014.

42. Kang BY, Kim S, Lee KH, Lee YS, Hong I, Lee MO, Min D, Chang I, Hwang JS, Park JS, et al: Transcriptional profiling in human HaCaT keratinocytes in response to kaempferol and identification of potential transcription factors for regulating differential gene expression. Exp Mol Med 40: 208-219, 2008.

43. Ryu J, Kwon MJ and Nam TJ: Nrf2 and NF- $\kappa$ B signaling pathways contribute to porphyra-334-mediated inhibition of UVA-induced inflammation in skin fibroblasts. Mar Drugs 13: 4721-4732, 2015. 
44. Aiello $\mathrm{S}$ and Noris M: Klotho in acute kidney injury: Biomarker, therapy, or a bit of both? Kidney Int 78: 1208-1210, 2010.

45. Basile DP, Anderson MD and Sutton TA: Pathophysiology of acute kidney injury. Compr Physiol 2: 1303-1353, 2012.

46. Simmons EM, Himmelfarb J, Sezer MT, Chertow GM, Mehta RL, Paganini EP, Soroko S, Freedman S, Becker K, Spratt D, et al; PICARD Study Group: Plasma cytokine levels predict mortality in patients with acute renal failure. Kidney Int 65: 1357-1365, 2004.

47. Rewa $\mathrm{O}$ and Bagshaw SM: Acute kidney injury-epidemiology, outcomes and economics. Nat Rev Nephrol 10: 193-207, 2014

48. Maruyama T, Yamamoto S, Qiu J, Ueda Y, Suzuki T, Nojima M and Shima H: Apoptosis of bladder cancer by sodium butyrate and cisplatin. J Infect Chemother 18: 288-295, 2012.

49. Wang M, Liu ZM, Li XC, Yao YT and Yin ZX: Activation of ERK1/2 and Akt is associated with cisplatin resistance in human lung cancer cells. J Chemother 25: 162-169, 2013.

50. Brechbuhl HM, Kachadourian R, Min E, Chan D and Day BJ: Chrysin enhances doxorubicin-induced cytotoxicity in human lung epithelial cancer cell lines: The role of glutathione. Toxicol Appl Pharmacol 258: 1-9, 2012.

51. Wang R: MoYung KC, Zhao YJ and Poon K: A Mechanism for the temporal potentiation of genipin to the ctotoxicity of cisplatin in colon cancer cells. Int J Med Sci 13: 507-516, 2016.

52. Yan D, An G and Kuo MT: C-Jun N-terminal kinase signalling pathway in response to cisplatin. J Cell Mol Med 20: 2013-2019, 2016.

53. Perkins ND: Integrating cell-signalling pathways with NF-kappaB and IKK function. Nat Rev Mol Cell Biol 8: 49-62, 2007.

54. Basak $S$ and Hoffmann A: Crosstalk via the NF-kappaB signaling system. Cytokine Growth Factor Rev 19: 187-197, 2008.

55. Hayden MS and Ghosh S: Shared principles in NF-kappaB signaling. Cell 132: 344-362, 2008.
56. Kim J, Long KE, Tang K and Padanilam BJ: Poly(ADP-ribose) polymerase 1 activation is required for cisplatin nephrotoxicity. Kidney Int 82: 193-203, 2012.

57. Lee S, Kim W, Moon SO, Sung MJ, Kim DH, Kang KP, Jang YB, Lee JE, Jang KY and Park SK: Rosiglitazone ameliorates cisplatin-induced renal injury in mice. Nephrol Dial Transplant 21: 2096-2105, 2006.

58. Al-Lamki RS, Lu W, Finlay S, Twohig JP, Wang EC, Tolkovsky AM and Bradley JR: DR3 signaling protects against cisplatin nephrotoxicity mediated by tumor necrosis factor. Am J Pathol 180: 1454-1464, 2012.

59. Benedetti G, Fokkelman M, Yan K, Fredriksson L, Herpers B, Meerman J, van de Water B and de Graauw M: The nuclear factor $\kappa \mathrm{B}$ family member RelB facilitates apoptosis of renal epithelial cells caused by cisplatin/tumor necrosis factor $\alpha$ synergy by suppressing an epithelial to mesenchymal transition-like phenotypic switch. Mol Pharmacol 84: 128-138, 2013.

60. Sahu BD, Tatireddy S, Koneru M, Borkar RM, Kumar JM, Kuncha M, Srinivas R, Shyam Sunder R and Sistla R: Naringin ameliorates gentamicin-induced nephrotoxicity and associated mitochondrial dysfunction, apoptosis and inflammation in rats: Possible mechanism of nephroprotection. Toxicol Appl Pharmacol 277: 8-20, 2014

61. Taye A and Ibrahim BM: Activation of renal haeme oxygenase-1 alleviates gentamicin-induced acute nephrotoxicity in rats. J Pharm Pharmacol 65: 995-1004, 2013.

62. Sepand MR, Ghahremani MH, Razavi-Azarkhiavi K, Aghsami M, Rajabi J, Keshavarz-Bahaghighat H and Soodi M: Ellagic acid confers protection against gentamicin-induced oxidative damage, mitochondrial dysfunction and apoptosis-related nephrotoxicity. J Pharm Pharmacol 68: 1222-1232, 2016. 